\title{
The Contribution of Submerge, Floating, and Gliding Ability on Swimming Distance Ability for First-Year College Students
}

\author{
Badruzaman Badruzaman*, Agus Rusdiana, Angga M Syahid \\ Faculty of Sport and Health Education \\ Universitas Pendidikan Indonesia \\ Bandung, Indonesia \\ *badruzaman@upi.edu, agus.rusdiana@upi.edu,angga_syahid@upi.edu
}

\begin{abstract}
The submerge, float, and glide ability are first or basic factor that can determine a person is able to swim naturally and can also be easier when learning swimming skills. The aim of study was to investigated contribution of submerge, floating, glade as basic swimming ability on swimming distance ability. Forty student colleges sport science $(n=26)$ and Mathematical $(n=14)$, age range 19 to 21 years (female 17), and (male 23). Subject category of beginner swimmers. They are semester III, and are enrolled in 2017. The applied test have been constructed in order to submerge, floating, gliding ability, as predictor and swimming distance ability as achievement reference standard. The study uses descriptive predictive method. Data collection Instruments use direct test in water. Descriptive statistics analysis (mean, St. d, minimal, maximal, and range). Inferential analysis of prediction using Person partial correlation and multiple linier regressions for predictive validity. Results; coefficient correlation submerge with floating $r=0.60$ (sig. $p>0.00$ ), moderate category. Submerge with gliding $r=0.34$ (sig. $p>0.034$ ), low category. Submerge with swimming distance (reference standard) $\mathbf{r}=\mathbf{0 . 5 3}$, $\mathbf{r}=0.28(28 \%)($ sig. $p>0.00)$, moderate. Floating with gliding $r=$ 0.33 (sig. $p>0.04$ ), low category. Floating with swimming distance $r=0.32, r 2=0.10(10 \%)$ (sig. $p>0.04)$, low category. Gliding with swimming distance $=0.38, \mathrm{r} 2=0.14(14 \%)$ (sig. $\mathrm{p}>$ 0.02), low category. All three factor variables have a positive relationship internal factor, but it is in the moderate and low category. The three components of the basic swimming ability as a predictor has a contribution to the ability of swimming distance of beginner level students with a value coefficient determination of $33 \%$. The remaining $0.67 \%$ resulted from the other ability. Physical education or beginner swimming trainers should teach these basic skills first before learning swimming techniques.
\end{abstract}

Keywords: contribution, floating, gliding, submerge, swimming distance ability

\section{INTRODUCTION}

Swimming differs from other types of sports in several aspects. The first and maybe the most obvious difference is the peculiar substance of water [1]. Students who showed a higher anxiety level, especially during the first swimming classes, achieved lower results in swimming skill test [2]. Swimming as sport is practiced by both sexes and indifferent ages according to their abilities. It differs from the remaining other sport activity, since aquatic milieu is considered a basis for progress by using arms, leg and trunk, and on the other hand it represents individuals ability to interact with aquatic milieu that differs from land milieu in which he lives raising individual's efficiency physically, skilfully, and psychological and reaching multi-aspects balanced education [3]. Therefore, many facts found by people who have difficulty doing swimming, can be caused by lack of interaction with the water environment. The results of previous studies show; that most of our athletes were unable to swim. There were 11 athletes who managed to cover 10 meters water distance, but four of them did not swim correctly, two reached 11-19 meters distance, but only one swam 25 meters [4]. In a study of children $(\mathrm{N}=70)$ who had swim $25 \mathrm{~m}$ and been declared 'swimmers,' one quarter $(26 \%)$ were unable to enter deep water by either a jump or dive [5].

To be able to have the ability to swim, one must have the basics needed in the water environment as a condition to support the ability to swim. And the first time is the ability to put the head in the water to feel the condition of the body while in the water. Therefore, when man enters water for the first time, he encounters many new situations, strange sensations, and an almost enter different environment [6]. Every skill in sports has its own characteristics such as swimming in water. The main characteristic is the condition of water which requires a person's body to enter the water. As long as the demands to dive the body into water are difficult, the ability to float the body to the surface of the water will also be difficult. This also affects subsequent abilities such as gliding, and footwork or arms to push at certain distances. When in the water, some people can easily float naturally, because it is related to the law of Archimedes. But there are still many who are difficult to float, because of the feeling of fear of water, or the mechanical fault of the body's factors in water. To be able to float the body above the surface of the water, one must have the ability to dive head into the water calmly first. If this first stage can be done calmly, then to be able to float the body will be easy. For that, start practicing by putting your face in the water. If you already feel confident, then other parts of the body will accompany unnoticed [7]. 
The ability to dive your head into the water, and float your body to the surface of the water calmly, is a basic factor that must first be possessed by someone as a condition to be able to swim at a certain distance. Under water submersion is a very importance element in learning to swim, and it usually takes a considerable amount of time to chive. It also requires courage and self-confidence. The ability to submerge with open eyes substantially advanced the learning process [4]. After succeeding in the first stage, the ability to float the body will be easier. The ability of a body to float (that is, to maintain a stationary position at the surface of the water) is of some importance in most aquatic sports. In swimming, for instance, a person's floating ability can influence success at both beginner and championship levels. Logically, a person who is able to float with ease is likely to learn go to swim more readily than one who floats only with difficulty or not at all [8]. The three components of this special basic ability are fundamentals, the main abilities that must be possessed by everyone who will learn to swim. Because it can determine the ability to master one's swimming skills easily. Analysis of unsafe techniques in clear recommendations with regard to head first entry [5]. The key to being able to swim is being able to float. When one can float, he or she can easily make any swimming movements [9]. Floating. Closely related to breathe control, bouyancy control is a key element in the teaching of water competent. It is widely accepted as foundational for water competency [10].

For a teacher, instructor or swimming coach who provides swimming learning, first must know the conditions or initial status of this special basic ability, because it will determine success towards the achievement of learning objectives. Clearly, we can better predict behaviour when we have more knowledge of the specific situation and how people tend to respond to it [11]. Through this study, researchers want to explore the basic components of swimming such as; the ability to dive, float and glide as factors that can determine or contribute to the ability to swim distance. And what is the relationship between these three factors. In the teaching of swimming, there has been a marked tendency for teachers to teach the content specified in test [12]. The setting of single item achievement test as criteria to measure beginning swimming is undoubtedly an important factor in narrow, "campaign" types of courses which are predominantly advocated by the social organizations serving youth. With the goal in view of producing a sound educational experience, graduated in nature, and comprehensive enough to insuring the development of well-rounded aquatic ability, some modification of fundamental nature is need in the testing program.

From the results of previous studies, the research theme has not been found. Then this study is a new study at this time.

The AWCS has set a minimum level (level 4 of the Swimming and Survive Program or the equivalent) that all children should achieve before leaving primary school [13]. Ensuring all children receive these skills is a key challenge for state and territory education systems that are moving away from compulsory swimming and water safety skills as part of the curriculum [14]. Actual performance evaluation was also used in identifying the swimming ability level of the respondents through the use of a rubric. The question which was validated through content validation was used to assess the purposed freestyle swimming skills improvement program for female students of AUF. The level of fear degree has reduced after learning of basic swimming skill, which shows that of basic swimming skills has the effect of reducing the level of fear degree in the aqueous medium [15]. Previous studies show almost the same facts; in a pilot study, children able to swim only $10-15 \mathrm{~m}$ but who did so comfortably and were skilled at floating in deep water, were able to swim $10 \mathrm{~m}$ [5].

\section{MethodS}

\section{A. Participants}

Research subject consisted of 40 Indonesia of Education University students, consisted of 25 students in sport science study programs and 15 mathematics study program students (28 male and 12 female). They are in semester III, class of 2017, ranging in age between 19 to 20 years. Subjects as beginner swimmer who have not been able to swim at distance of $25 \mathrm{~m}$. A beginner was any subject who could not swim one length ( 25 yd) [16]. Subjects had not been given swimming learning programs when attending lectures.

\section{B. Instrument}

Instruments in the form of basic swimming ability tests, the content of which adopts some component parts of the Red Cross. The beginner's Test as set forth by the American Red Cross, that all members of the physical education department offered to take the Water Safety Course of that organization and thus teach our swimming by the American Red Cross [17]. Eight skill elements emerged finally as both irreducible and irreplaceable within beginner swimming course. Entry in to deep water, upon submersion, regain surface, level off and swimming, surface dive and swimming underwater with comfort, acquisition of at least two rudimentary stroke, one on the front, one the back, breath in relaxed way and in a manner coordinated to demands of the stroke, change body position in water, change direction of travel, and Remain float (i.e., stop and rest with minimal movement; no movement is necessary for prepubescent children and for women, all of whom can float; Stallman, 1997 [10]. In this study include; the ability to dive test (seconds), ability to floating (seconds), and ability to glide (distance). As a predictor of a complete basic swimming ability test (legs, arms, and breathing) in the style of choice. Measurement of distance travelled [17]. The ultimate goal of teaching of swimming, is of course, to require the student to propel himself through the water for a designated distance, usually sixty to one hundred feet.

\section{Procedures}

Data collection tests were carried out in the Indonesia University Education swimming pool, the depth of the pool was as high as a student's chest $(1.30 \mathrm{~cm}$.), the water temperature was 28 degree Celsius. The test is carried out twice in a oneweek time span for all items. Before being given a test, first all subject to warm up on land for 10 minutes, and warm up in water for 10 minutes. Furthermore, test is carried out for each component for all subjects. The first test is the ability to dive your head into the water, then the tests floats the body to the 
surface of the water, the glide test, and the last basic swimming ability test is complete.

The implementation of the test for each component is done in groups of 5 people. The dive test procedure, the first tested stands facing the wall of the pool, both hands holding the iron, after hearing the sound of the whistle, all testes must simultaneously start to put all of his head into the water.

And stop watch will record it according to its ability to survive in water. Measurement of time in units of seconds will be recorded, when the whole head has come out from the surface of the water.

The procedure floating test, the first subject is ready to stand facing the pool wall with a distance of one meter from the wall. When you hear the whistle, all subjects simultaneously put their entire bodies in to the water, and float their bodies until they float to the surface of the water, and keep it as long as possible. The measurement will record when the foot of the tested has touched the floor. Unit of measurement with time per second.

The body position of the tuck float is easy to assume and to relax in. The arms and legs are kept in control, and body buoyancy is most effective in this position. The position of the head reduces the possibility of water entering the nasal passages and causing discomfort. And, finally, the beginner finds it quite easy to regain his feet from the tuck float [18].

Gliding test procedure. Tested preparation stand leaning against the pool wall, bend one leg and attach it also to the pool wall. At the sound of the whistle, the tested repulses the foot of the pool as hard as possible to encourage the body to glide over the surface of the water. Allow the body to slide as far as possible. When sliding, the body is formed horizontally both arms are closed at both ears and leaned forward. Measurements will be recorded with a stopwatch, when the tested feet touch the floor. The unit of measurement based on the distance travelled measured starting from the pool wall, to the position of the end of the arm when stopped. (during sliding, there is no help from other limb, arms and legs. The swimmer was modelled as if he were gliding underwater in a streamlined prone position, with hands overlapping, head between the extend [19].

Swimming distance testing procedure. Preparation subjects stood on the edge of the pool with hips attached to the wall. On the whistle signal, the subject swims as far as possible with the chosen style. Measurement is recorded based on the distance travelled. Measurement start from the pond wall, until the point the subject stops and stands.

The implementation of the test was assisted by three senor students. Each task is to prepare the tested, hold the stopwatch, take measurements with meters, and recorded the results. The first and the second test are done in a span of one week. And is carried out at the same time, place, and procedure.

\section{Statistical Analysis}

Descriptive statistical methods were used for calculation of means, standard deviations, score minimal, score maximal, range. The sample normality was determined by Kolmogorov-
Smirnov test (Lilliefors significance correction). For the analysis of the contribution of factors to the dependent variable as a predictor, with inferential statistic; normality, testing, partial correlation Person products moment, (r) is used determine interclass factors. Correlation value $<0.4$ represented poor correlation, 0.4 to 0.7 fair, 07 to 0.9 good and $>0.9$ excellent [20]. To test the contribution used the calculation of coefficient determination (r2) with multiple linear regressions. All the analyses, IBM SPSS25 package was used [21].

\section{RESULTS}

Descriptive data based on the results of submerge, floating, gliding, and basic swimming abilities for distance, by calculating the mean, standard deviation, minimum mean, maximum mean, and range. The results of tests of the ability to submerge, floating, glide, and the ability to swimming distance this study displayed at table 1 bellow:

TABLE I. DESCRIPTIVE DATA BASIC SWIMMING ABILITY

\begin{tabular}{|l|l|c|c|c|c|c|c|}
\hline No & Component & $\mathbf{N}$ & mean & Min & Max & range & St.d \\
\hline 1 & $\begin{array}{l}\text { Swim dis. } \\
(\mathrm{m})\end{array}$ & 40 & $8.52 \mathrm{~m}$ & 2 & 15 & 13 & 3.72 \\
\hline 2 & $\begin{array}{l}\text { Submerge } \\
(\mathrm{s})\end{array}$ & 40 & $16.22 \mathrm{~s}$ & 1.01 & 38.45 & 37.44 & 9 \\
\hline 3 & Floating (s) & 40 & $15.24 \mathrm{~s}$ & 0.78 & 34.62 & 33.84 & 9.3 \\
\hline 4 & Gliding (m) & 40 & $4.61 \mathrm{~m}$ & 2 & 7 & 5 & 1.12 \\
\hline
\end{tabular}

Table 1 shows a description the average student submerges ability of 16.22 seconds. The lowest there are student who are only able to submerge 1.01 second, and the longest is 38.45 seconds. The ability to float students averaged 15.24 seconds, almost the same as the ability to submerge. The lowest there are students who are only able to float at 0.78 second, and the longest is 34.62 seconds. Ability to glide (prone) students average 4.1 meters, the shortest is only able to 2 meter and farthest $5 \mathrm{~m}$. Swimming distance ability (freestyle/choice) ability of the average student as far as 8.52 meters, the shortest is only capable of 2 meters, and farthest 15 meters.

TABLE II. INTERCLASS CORRELATION TEST RESULT BETWEEN COMPONENT AS PREDICTOR.

\begin{tabular}{|l|l|l|l|l|}
\hline Component & Submerge & Float & Glide & $\begin{array}{c}\text { Swimming } \\
\text { Distance }\end{array}$ \\
\hline Submerge & 1 & 0.60 & 0.34 & 0.53 \\
\hline Float & 0.60 & 1 & 0.33 & 0.32 \\
\hline Glide & 0.34 & 0.33 & 1 & 0.39 \\
\hline Distances & 0.53 & 0.32 & 0.39 & 1 \\
\hline
\end{tabular}

Table 2 show the results of interclass correlation testing, correlation between submerge ability and floating, correlation coefficient $\mathrm{r}=0.60, \mathrm{r} 2=0.36(36 \%)$ (sig. $\mathrm{p}>0.00)$. Both components have positive and significant correlations with moderate categories. The ability of submerge and gliding correlation coefficient values $\mathrm{r}=0.34, \mathrm{r} 2=0.12(12 \%)$ (sig. $\mathrm{p}$ $>0.03$ ), have positive and significant correlation with low categories. The ability of submerge with swimming distance ability coefficient correlation values $\mathrm{r}=0.53, \mathrm{r} 2=0.28(28 \%)$. 
Showing positive and significant correlation at moderate categories. But the coefficient of determination shows in the low category. The floating ability with gliding coefficient correlation $r=0.33$ (sig. $\mathrm{p}>0.04$ ) and $\mathrm{r} 2=0.11(11 \%)$ showing positive and significant, in the low category. The ability to glide with swimming distance ability coefficient correlation $\mathrm{r}=0.39$ (sig. >p 0.01) and $\mathrm{r} 2=0.15(15 \%)$ showing positive and significant, in the low category.

TABLE III. The Result OF The REgRESSION ANALysis OF ThE CONTRIBUTION OF FACTORS TO THE PREDICTION REFERENCE

\begin{tabular}{|l|c|l|l|l|}
\hline Model & R & R Square & $\begin{array}{c}\text { Adjusted R } \\
\text { Square }\end{array}$ & $\begin{array}{c}\text { Std. Error of The } \\
\text { estimate }\end{array}$ \\
\hline 1 & $0.576 \mathrm{a}$ & 0.331 & 0.275 & 3.17310 \\
\hline
\end{tabular}

Table 3 shows contribution test results with coefficient determination; $\mathrm{R}=0.576^{\mathrm{a}}, \mathrm{R}$ Square $=0.331$, Adjusted $\mathrm{R}=$ 0.275 , Std. Error of the estimate $=3.17310$. Can be said coefficient determination to be a significant. Other analysis result using ANOVA b; value $\mathrm{F}=5.943 \mathrm{Sig}$. $0.002 \mathrm{P}<0.05$. Shows that all three factors have a significant influence on the prediction reference. The results of the analysis using T-test, submerge ability has a $\mathrm{T}$ score $\mathrm{T}=2.785 \mathrm{Sig}$. $0.008<\mathrm{p}=0.05$. Submerge ability can be said to have a significant influence on the ability to swim distance. Gliding ability has $\mathrm{T}$ score value = 1.602 sig. $0.118 \mathrm{p}>0.05$. The ability to glide has a significant effect on to swim distance ability.

\section{DISCUSSION}

The main purpose of this study was to investigation the ability to submerge, floating, and glide as a predictor and contribute to the basic abilities of swimming distance for beginner level students.

Based on the results of the multi-linier regression analysis, the three components of basic swimming ability; submerge, floating, and gliding, have a significant effect on the basic ability of swimming distance with a contribution value of 33.1 $\%$, even at a low level. This can be understood, because the three components are not a factor as a driving force to produce the body's power (propulsion) going forward, but only as a basic capital to support the propulsion. The rate of power production in swimming, is obtained predominantly from the results of the movements of the legs and arms. The propulsive phase of the arm motion was observed to generate strong vertical structures which subsequently travel along the body and toward the kicking legs. Most of the arm propulsion was generated when the hands were moving backward [22].

The three components are basic that must be possessed first by someone when learning to swim. This is to make it easier to do leg and arm movements to push to body forward. As long as these components have not been obtained correctly, the correct leg and arm movements will be difficult. Because the movements of the legs and arms will be easy with the right technique, if the body is in a floating properly and calmly.

When a person enters water for the first time, he experiences strange sensations in an almost entirely different environment. The physical, physiological, and mental effects of water may so disturb him that he must be conditioned and adjusted to this new environment before he can gain a sense of security, pleasure, relaxation, and achievement-vital ingredients to the learning process of the non-swimmer [18]. Swimming may be defined as floating while propelling your body from one point to another. Basic to all swimming is the fact that your body is lighter than water and floats [23].

After the body can float easily, the body must be formed parallel to water (streamline), so that the body glides smoothly. This accomplished through a series of orientation exercises such as the author has prepared, for example: walking, jumping, dipping, submerging, opening eyes and mouth under water, breathing, floating, balancing, sliding [6].

Based on observational data records, their limbs and arm movements techniques are mostly $(87 \%)$ still rough, and their body positions are still not stretched, so their swimming distance is still relatively short. In accordance with previous studied. There were 11 athletes who managed to cover 10 meters water distance, but four of them did not swim correctly, two reached 11-19 meters distance, but only one swam 25 meters [4].

The biggest contribution was obtained from the submerge ability by $28 \%$. This can also be understood, because the ability of their swimming distance is not very view who the breath, because they do not have the ability to take breath. So those who hold their breath long in water, will be able to reach further distances, compared to those who have the ability to submerge short.

Their average submerge ability of 16 seconds is almost the same as the ability to float 15 seconds. The ability to glide accounts for $15 \%$ smaller than the ability to submerge. This is because the ability to glide only serves to maintain body balance, and maintaining the body's position to remain horizontal. Buoyancy and balance, the split-second timing between each arm, and the continues changing body alignments through the stroke are contributing factors that enable a swimmer to produce continuing momentum throughout the stroke [24].

Observations during the test explained that on average they did not have the ability to maintain body position when sliding, were not calm, and were not balanced, and could not yet form the body in a perfect streamlined position. Unskilled swimmers frequently have inadequate body roll. Also common among unskilled swimmers is the tendency to roll and wobble all over the place. These unstreamlined positions do not facilitate smooth flow of water over the body [25]. So their limbs that are not horizontal, make the inhibiting factor of the rate of power [19]. When gliding, the swimmer notices the passive drag, which is cause mainly by the shape and size of the body and the velocity and depth of the glide. The results from previous study show that most of our athletes were unable to swim. There were 11 athletes who managed to cover 10 meters water distance, but four of them did not swim correctly, two reached 11-19 meter distance, but only one swam 25 meter. Swimming technique was given very low score, the average being 0.5 out of the possible 10. Gliding after push off from the wall. The obtained data show that our athletes achieved a similar distance when gliding spin or front $(\mathrm{p}>0.05)$ Distance front float 6.9 (2.1) and 
back float 7.3. (1.9) [4]. During immersed swimming below a certain swimming depth (for human swimmers below about 0.8 $\mathrm{m}[26]$.

Based on the results of the partial correlation analysis, the relationship between the ability to dive with the ability to swim distance has a positive correlation coefficient with moderate categories of $\mathrm{r}=0.53(\mathrm{r} 2=0.28 \%)$. Diving test results can be predicted to have a contribution to the ability of swimming distance by $28 \%$. The ability to float has a contribution of $10 \%$ to the ability to swim distance is smaller than the ability to dive. And the ability to glide has a contribution of $15 \%$ of the ability to swim distance. Those traits have more than $50 \%$ share variance $(\mathrm{r} 2>50$; recall again the coefficient of determination, or in other words, that have correlations of 0.70 , were said to be general in nature [11]. Any two tests that had correlations of 0.70 or less were said to be specific. Because of the magnitude of the correlations that chose, most motor ability test were found to be specific in nature. The cause-and-effect implication from this was that traits should be trained specifically. Each student in the class is required to swim his greatest distance on the first attempt, using one or all of the strokes he has learned.

\section{CONCLUSION}

The results of the regression analysis of basic swimming abilities include; the ability to dive, float and glide as a predictor, has a significant contribution to the ability of swimming distance of students at the beginner level by $33 \%$. The remaining $67 \%$ can be determined by other factors, namely the propulsion of the movements of the legs, arms. Although the contribution of the three basic swimming abilities is relatively low, it has a very vital function as a basic capital that can determine in facilitating the achievement of swimming abilities, as well as for the achievement of mastery of skills in swimming learning. Of the three basic components of the special swimming ability, the biggest contribution to the ability to swim distance is the ability to dive by $28 \%$, the ability to glide $15 \%$, and the ability to float $10 \%$.

Practical implications, for physical education teachers, swimming trainers / instructors, before giving swimming learning to begin for beginners, first conduct tests to measure all three basic abilities; diving, floating, and gliding, so that more clearly known characteristics of its ability in activities in water, as a potential that can support the achievement of swimming learning outcomes. So that it can precisely determine the learning program in accordance with the level of ability it has. These three basic swimming abilities must be taught as a preliminary stage, to introduce to the water environment, so that students are able to adapt. This special basic ability of swimming must be given before being taught the techniques of leg movements, arms, and coordination.

\section{ACKNOWLEDGMENT}

The authors would like to thanks to the Indonesia University of Education for allowing using swimming pool facilities during data collection. And lectures for sport science, and students sport science, and mathematical of program study who have participated in study.

\section{REFERENCES}

[1] B. Melinda et al., "Examinitaion of Teaching-Learning Process in Swimming Applying Chaffers' System of Interaction Catagories," Academic Journals Education Research and Review, vol. 2(4), pp. 064073, April 2007.

[2] M.T. Arifin, "The Effect of Swimming Abilityon the Anxiety Levels of Famale College Students," Asian Social Science, Canadian Center of Science and Education, vol. 9(15), 2013.

[3] E.A. Zaghlol., "The Effect of Float Tools on Some Basic Skills Performance in Swimming and Some Physiological Variables for Students in Faculty of Psycal Education. Science, Movement and Health," vol. 14(1), 2014.

[4] B. Statkeiciene and T. Venckunas, "Athlets' Antropometrical Measurements ans Physical Capacity Influence on Learning Competetive Swimming Techniques," Acta Medica Lituanica, vol. 15(4), pp. 229-234, 2008.

[5] S. Robert et al., "From Swimming Skill to Water Competence: Towards a More Inclusive Drowing Prevention Future," International Journal of Aquatic Research and Education, vol. 10(2), 2017.

[6] D.A. Armbruster, "Teaching Beginners to Swimm," The Journal of Health and Physical Education, vol. 7(4), pp. 242 - 275, 2015.

[7] H. David, Belajar Berenang. Pionir Jaya: Bandung, 2008.

[8] J.G. Hay, The Biomechanics of Sports Techniqes. Prentice-Hall: USA, 1993.

[9] U. Meirizal, "Swimming Learning Model Using Rope As Aid for Beginners," Advances in Social Science, Education and Humanities Research, vol. 174. [Internatioal Conferention on Education (ICE), Atlantis Press, 2017].

[10] R.K. Stallman et al., "The Teaching of Swimming Based on a Model Derived from the Causes of Drowning," International Journal of Aquatic Research and Education, vol. 2(4), 2008.

[11] J.R. Morrow et al., Measurement and Evaluation in Human Performance. USA: Human Kinetics, 2011.

[12] T.K. Cureton, "Standars for Testing Beginning Swimming. Research Quarterly," American Association for Healt, Physical Education and Recreation, Springfield College, Massachusetts, USA, vol. 10(4), pp. 5459, 2015.

[13] R.C. Franklin et al., "Learning to Swimm: What Influences Success?," International Journal of Aquatic Research and Education, vol. 9(3), pp. 8-1, 2015.

[14] P. Capitulo and J. Martin, "Assessment of a Proposed Freestyle Swimming Skills Improvement Program for Female College Students," International Journal of Physical Education, Fitness and Sports, vol. 4(1), March 2015

[15] A. Tame, "The Impact of Learning Some Basic Swimming Skills on Fear Level Degree Among Physical Education Students," The Swedia Journal of Scientific Research, vol. 3, March 2016.

[16] A. Holt, et al, Two Methods of Teaching Beginning Swimming. Research Quarterly, American Assiciation for Health, Physical Education and Recreation, Publisher: Routledge, London, 2013, vol. 41(3), pp. 371-377.

[17] M.A. Schaefer, "Theaching Swimming to the Slow Beginner," The Journal of Health and Physical Education, vol. 17(5), pp. 280-317, 2013.

[18] T.W. Taylor, "Tuck Float Skills for Beginning Swimmers," Journal of Healt, Physical Education, Recreation, vol. 28(4), pp. 18-80. 2015.

[19] M.L. Novais et al., "The Effect of Depth on Drag Duringthe Streamlined Glide," A Three-Dimensional CFD Analysis, Journal Human Kinetics, vol. 33, pp. 55-62, 2012.

[20] C. Tompestt et al., "Comparing Perofrmances of Fundamental Movement Skills and Basic Human Movements," A Pilot Study. Journal of Fitness Research, Australian Institut of Fitness, 2015.

[21] G. Pramesti, Mahir Mengolah Data Penelitian dengan SPSS 25. PT Elex Media Komputindo Kompas Gramedia: Jakarta, 2018.

[22] R.C. Cohen et al., "The Role of the Hand During Freestyle Swimming," Journal of Biomechanical Enginering, September 2015. 
[26] S. Hochstein and R. Blickhan, "Body Movement Distribution with Respect to Swimmer's Glide Position in Human Underwater Undulatory Swimming," Human Movement Science, vol. 38, pp. 305-318, 2014. 